\title{
Growth Response of Potato Cuttings (Solanum Tuberosum L.) Granola Lembang Varieties Results Of Tissue Culture To Giving Radix Up With Different Segments
}

\author{
Faisal Harianto $\left.P . .^{*}\right)$, Erny Ishartati'), Syarif Husen ${ }^{3)}$ \\ 1),2),3)Agrotechnology Department, Faculty of Agriculture and Animal Science, University of Muhammadiyah \\ Malang, Malang, 65144, Indonesia \\ *) Corresponding Author : haryantofaisal@gmail.com
}

\section{ABSTRACT}

Potato plants are propagated vegetatively with tubers. The difficulty of getting potato seeds with tubers is an obstacle in the supply of potato seeds, to overcome these obstacles vegetative propagation with cuttings can be a solution for the supply of potato seeds. This research used a factorial Randomized Block Design (RBD). The first factor is the type of Radix Up consisting of 4 levels, namely Z0 (control), Z1 (Radix Up 1), Z2 (Radix Up 2), and Z3 (Radix Up 3), the second factor is the number of segments consisting of 3 levels namely D1 (number of segment 1), D2 (number of segment 2), and D3 (number of segment 3). Observation variables included: when the roots appeared, plant height, number of leaves, and stem diameter.The results showed that there was an interaction between Radix Up types and the number of segments on the growth of potato shoot cuttings when the roots appeared, but there were no interactions on other observational variables. The Z1D3 treatment (Radix Up 1 and segment number 3) gives the fastest average value, which is the average when the root appears 4.33 days.

Keywords: Rootone F, Radix Up, Segments

\section{INTRODUCTION}

Potatoes (Solanum tuberosum L.) are vegetable commodities that receive development priority, because potato plants contain carbohydrates, are nutritious, and there are vitamins and minerals. Potato plants are growing rapidly in Indonesia in terms of cultivation and production making Indonesia one of the largest potato producing countries in Southeast Asia (Ummah dan Purwito, 2009).

Potato plants are propagated vegetatively with tubers. The difficulty of getting potato seeds with tubers is an obstacle in the supply of potato seeds, to overcome these obstacles vegetative propagation with cuttings can be a solution for the supply of potato seeds. Cuttings are a method of propagation of plants by using pieces of the plant body (roots, leaves, stems). Potatoes can be propagated vegetatively by means of shoot cuttings, namely by cutting young shoots. The success of cuttings is characterized by the formation of roots in the buds of potatoes that have been cut. To stimulate the formation of roots in potato shoot cuttings, it is needed growth regulators.

An effective growth regulator is needed to stimulate the formation of roots, shoots and leaves. Naphtalene acetic acid (NAA) is a plant growth regulators of the auxin group whose role is to increase the number of root fibers, stimulating root growth in plant cuttings. Benzine amino purine (BAP) is a plant growth regulators of cytokonin groups that play a role in stimulating cell division and growth of side shoots. Giberalin $\left(\mathrm{GA}_{3}\right)$ is a plant growth regulators that functions to stimulate flowering and fruit development in plants, as well as the formation of tubers.

This research aims to obtain the best concentration of the combination of $\mathrm{NAA}, \mathrm{BAP}$ and $\mathrm{GA}_{3}$ for the growth of potato cuttings.

\section{METHOD}

\section{Time and Place of Research}

The research was conducted in the green house of the Horticultural Garden of the East Java Agriculture Office, 
Sidomulyo Village, Bumiaji District, Batu City, from August 2018 - October 2018. The altitude of the study was 1000 meters above sea level.

\section{Tools and materials}

The equipment used in this redearch is, tray, polybag, seedbox, measuring flask, bunsen, pipette, sprayer, measuring cup, razor, razor, ruler, bottle, digital calipers, scales, cameras, buckets, and stationery.

\section{Experimental Design}

This research uses factorial randomized block design (RBD), with 3 replications consisting of 2 treatment factors. So that obtained 12 combinations and 3 replications. The combination of treatments as follows:

- Z0D1 : Control (Rootone F), number of segments 1

- Z0D2 : Control (Rootone F), number of segments 2

- ZOD3 : Control (Rootone F), number of segments 3

- Z1D1 : Radix Up 1 (NAA 0,7 ppm + BAP 0,7 ppm + $\mathrm{GA}_{3}$ 0,7 ppm), number of segments 1

- Z1D2 : Radix Up 1 (NAA 0,7 ppm + BAP 0,7 ppm + $\mathrm{GA}_{3}$ 0,7 ppm), number of segments 2

- Z1D3 : Radix Up 1 (NAA 0,7 ppm + BAP $\left.0,7 \mathrm{ppm}+\mathrm{GA}_{3} 0,7 \mathrm{ppm}\right)$, number of segments 3

- Z2D1 : Radix Up 2 (NAA 1,3 ppm + BAP $\left.1,3 \mathrm{ppm}+\mathrm{GA}_{3} 1,3 \mathrm{ppm}\right)$, number of segments 1
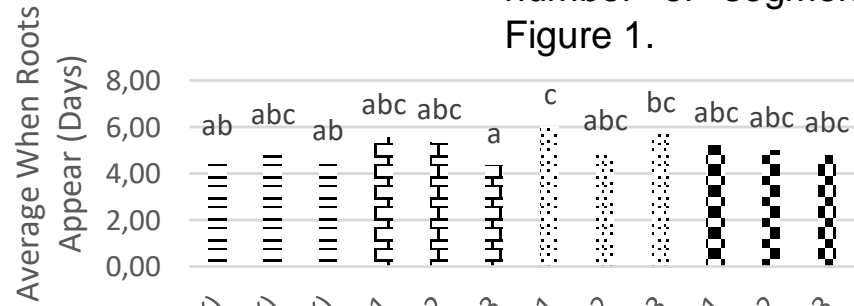

(1)

Figure 1. When Roots Appear With Radix Up Treatment and Number of Sections.

Description :

- The mean value accompanied by the same letters between treatment combinations shows no significant difference according to the BNJ test level of $5 \%$.

- Z2D2 : Radix Up 2 (NAA 1,3 ppm + BAP 1,3 ppm + GA ${ }_{3}$ 1,3 ppm), number of segments 2

- Z2D3 : Radix Up 2 (NAA 1,3 ppm + BAP 1,3 pp $\left.+\mathrm{GA}_{3} 1,3 \mathrm{ppm}\right)$, number of segmets 3

- Z3D1 Radix Up 3 (NAA 2 ppm + BAP 2 ppm $\mathrm{GA}_{3} 2 \mathrm{ppm}$ ), number of segments 1

Z3D2 : Radix Up 3 (NAA 2 ppm + BAP $2 \mathrm{ppm}+\mathrm{GA}_{3} 2 \mathrm{ppm}$ ), number of segments 2

- Z3D3 : Radix Up 3 (NAA 2 ppm + BAP $\left.2 \mathrm{ppm}+\mathrm{GA}_{3} 2 \mathrm{ppm}\right)$, number of segments 3

Observation variables included: when the roots appeared, plant height, number of leaves and stem diameter. The observational data were analyzed using the $\mathrm{F}$ test at a level of $5 \%$, if there was a real effect between treatments a further test of the BNJ level of $5 \%$ was conducted. Also performed Contrast Orthogonal Test to determine the difference between treatment and control. Analysis of data using the 2013 Microsoft Excel program.

\section{RESULT AND DISCUSSION}

\section{When Root Appears}

Based on the results of the analysis of the variety when the roots appear, there is an interaction between the types of Radix Up and the number of segments that have a significant effect. The mean values when the treatment roots appear like Radix Up and the number of segments are presented in Figure 1. 
In Figure 1 shows that the mean when the root of treatment Z1D3 (Radix Up 1, number of segment 3) appeared significantly different from the treatment of Z2D1 (Radix Up 2, number of segment 1) and Z2D3 (Radix Up 2, number of segment 3), whereas with other treatments not real different.

\section{Plant Height}

Based on the analysis of plant height variations showed no significant difference between treatment and control. Plant height showed no significant interaction between treatments such as Radix UP and number of segments. Separately the treatment of the number of sections significantly affected the age of 7 and 28 DAP. The mean increase in height of treatment plants such as Radix Up and number of segment is presented in Figures 2, 3 and 5.

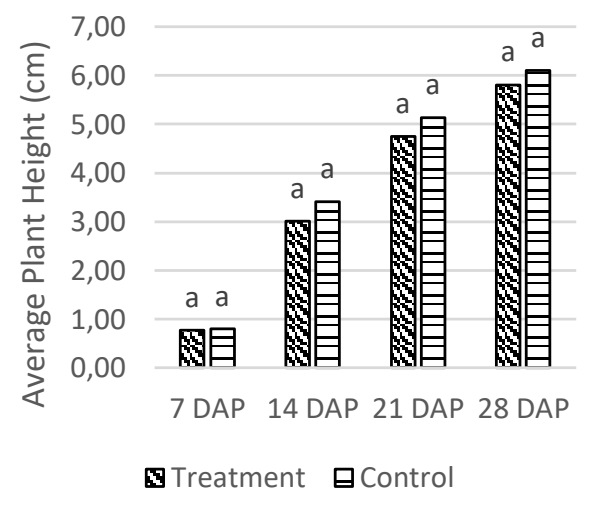

Figure 2. Average Height of Ages 7-28 DAP.

Description :

- The mean value accompanied by the same letters between treatment combinations shows no significant difference according to the BNJ test level of $5 \%$.

In Figure 2 shows that the average plant height showed no significant difference at all plant ages. Age of plants 7 to 28 DAP showed the highest average height of plants in the control.

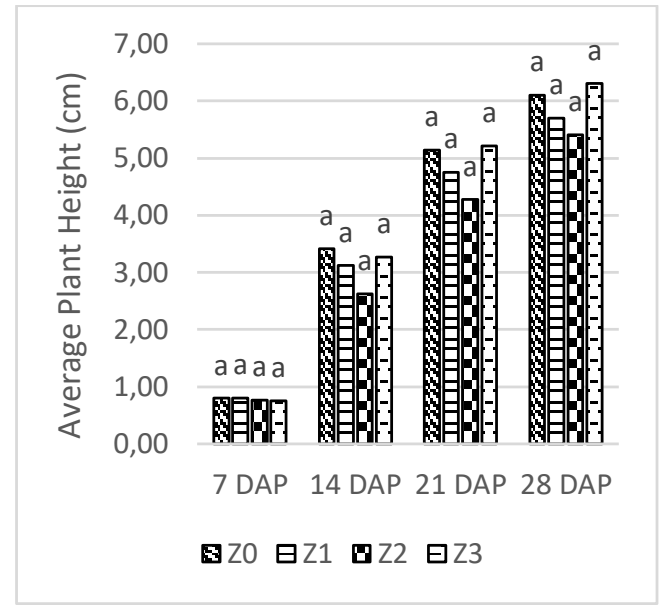

Figure 3. Average Height of Ages 7- 28 DAP with Kinds of Radix Up Treatment on Potato Buds.

Description :

- The mean value accompanied by the same letters between treatment combinations shows no significant difference according to the BNJ test level of $5 \%$.

In Figure 3 shows that the average height of treatment plants such as Radix Up shows no significant difference at all plant ages. Age of plants 7 and 14 DAP showed the highest mean height of plants at $\mathrm{ZO}$ treatment (control), while at 21 and 28 DAP showed the highest average height of plants at Z3 treatment (Radix Up 3).

In Figure 4 shows that the mean diameter of the treatment stem the number of sections significantly different at the age of 7 days, the average value of D3 (number of sections 3 ) is higher than D1 (number of segment 1) and D3 (number of segment 2). Plant age of 14 days after planting showed significantly different, mean value of D3 (number of sections 3) was higher than D1 (number of segment 1 ) and D2 (number of segment 2). 


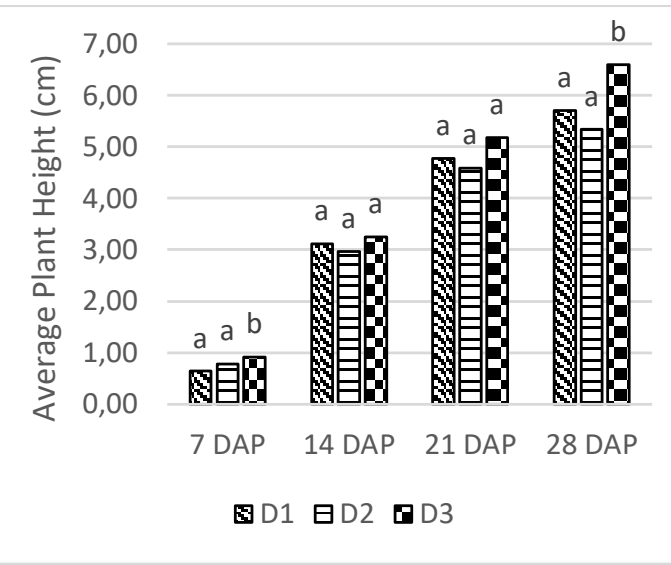

Figure 4. Average Height of Ages 7-28 DAP with Number of Section Treatment on Potato Buds.

Description :

- The mean value accompanied by the same letters between treatment combinations shows no significant difference according to the BNJ test level of $5 \%$.

\section{Number Of Leaves}

Based on the analysis of the variance in the number of leaves showed no significant difference between treatment and control. The number of leaves shows no significant interaction between treatments such as Radix Up and number of segments, as well as the effects separately from the two factors. The mean value of the number of treatment leaves such as Radix Up and number of sections is presented in Figures 5, 6 and 7.

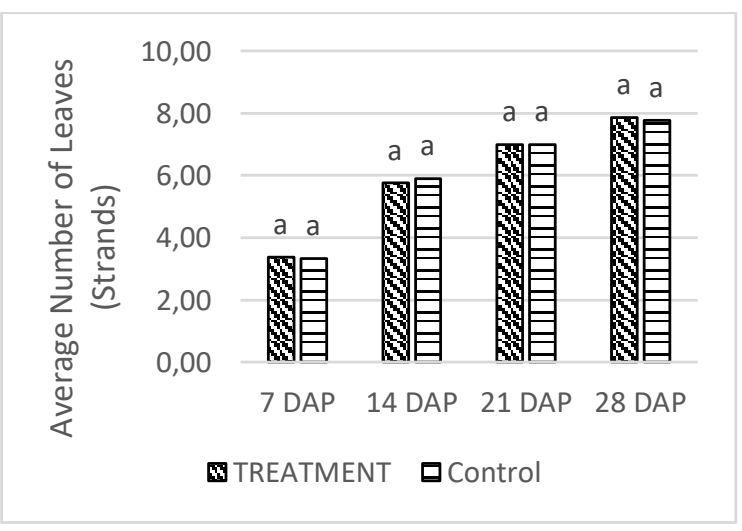

Figure 5. Average Number of Leaves Age 7-28 DAP.
Description :

- The mean value accompanied by the same letters between treatment combinations shows no significant difference according to the BNJ test level of $5 \%$.

Figure 5 shows that the average number of leaves was not significantly different at all plant ages. Age of plants 7, 14 and 28 DAP showed the highest mean number of leaves in the treatment, while at plant age 21 DAP showed the highest number of leaves in the control.

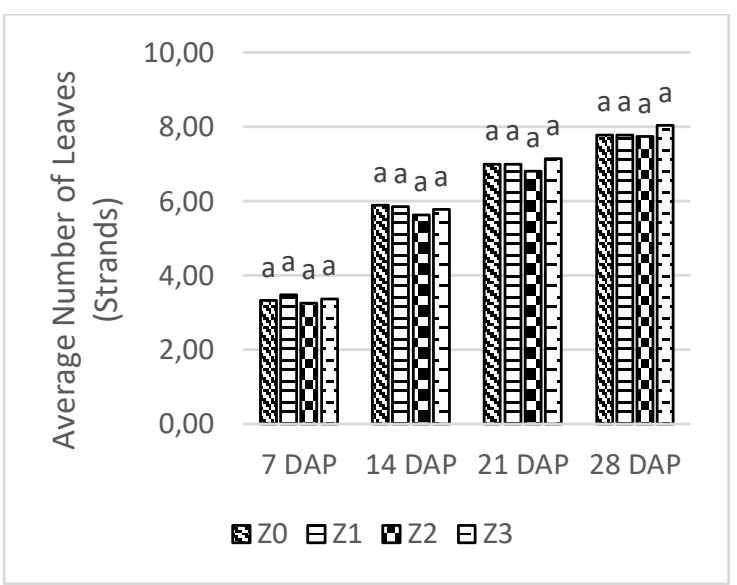

Figure 6. Average Number of Leaves Age 7 - 28 DAP with Radix Up Treatments on Potato Buds.

Description :

- The mean value accompanied by the same letters between treatment combinations shows no significant difference according to the BNJ test level of $5 \%$.

Figure 6 shows that the mean number of leaves of Radix Up treatment was not significantly different at all plant ages. Plant age of 7 days after planting showed the highest average number of leaves in treatment Z1 (Radix Up 1), age of plants 14 days after planting was highest in treatment Z0 (control), and at plant age 21 days after planting and 28 days after planting showed the highest number of leaves in treatment Z3 (Radix Up 3). 


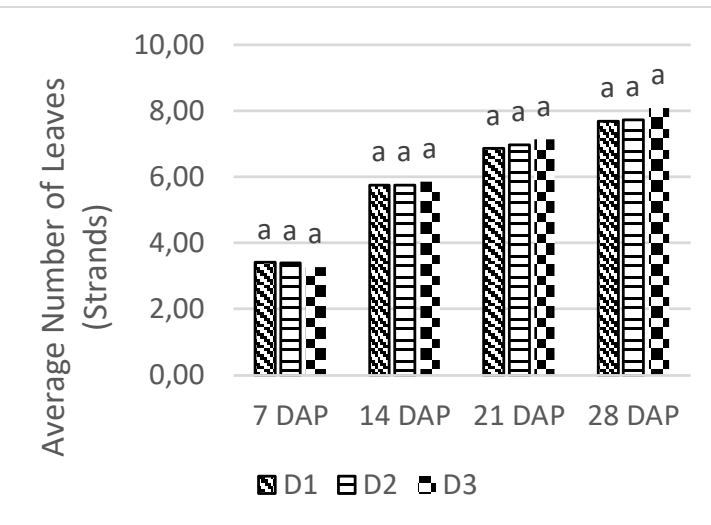

Figure 7. Average Number of Leaves Age 7 - 28 DAP with Number of Section Treatment on Potato Buds.

Description :

- The mean value accompanied by the same letters between treatment combinations shows no significant difference according to the BNJ test level of $5 \%$.

Figure 7 shows that the average number of leaves treated by the number of segments shows no significant difference at all plant ages. Age of plant 7 days after planting showed the highest number of leaves in treatment D1 (number of segment 1), while at age 14,21 and 28 DAP showed the highest number of leaves in treatment D3 (number of segment 3).

\section{Diameter Of Stem}

Based on the results of the analysis of the diameter of the rod shows that there are no significant differences between treatment and control. The diameter of the stem shows no significant interaction between treatments such as Radix Up and number of segments. Separately the treatment of the number of segments had a very significant effect at the age of 7 DAP and significantly affected at the age of 14 DAP. The mean increase in diameter of treatment rods such as Radix Up and number of sections is shown in Figures 8, 9 and 10.

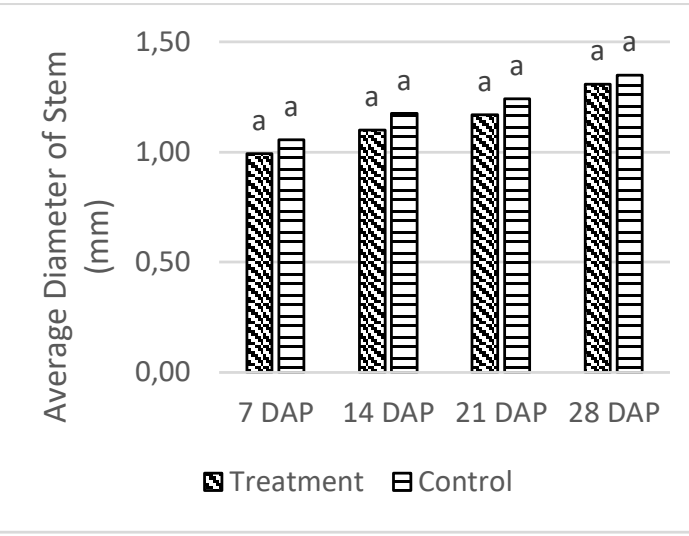

Figure 8. Average Diameter of Stem 7-28 DAP.

Description :

- The mean value accompanied by the same letters between treatment combinations shows no significant difference according to the BNJ test level of $5 \%$.

In Figure 8 shows that the mean diameter of the stem shows no significant difference at all plant ages. At the age of 7 DAP until 28 DAP showed the highest average stem diameter found in the control.

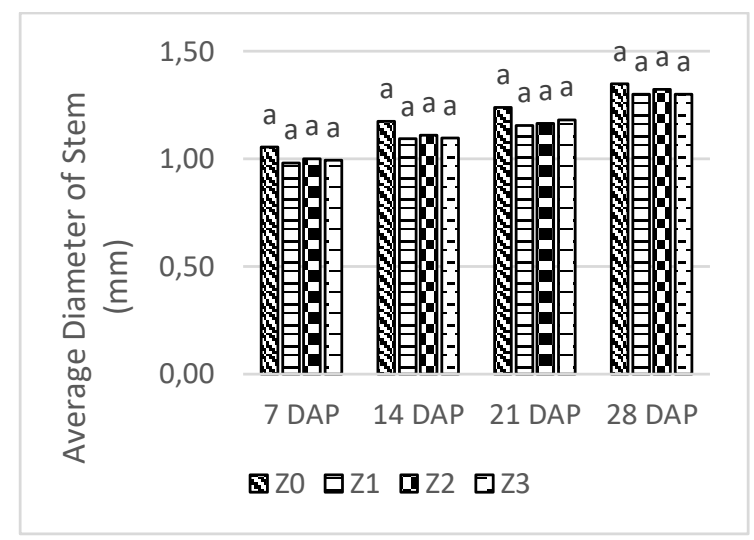

Figure 9. Average Diameter of Stem 7 - 28 DAP with Radix Up Treatments on Potato Buds.

Description :

- The mean value accompanied by the same letters between treatment combinations shows no significant difference according to the BNJ test level of $5 \%$. 
Figure 9 shows that the mean diameter of the treatment rods like Radix Up shows no significant difference at all plant ages. Plant age of 7 DAP to 28 DAP showed the highest mean stem diameter in the Z0 (control) treatment.

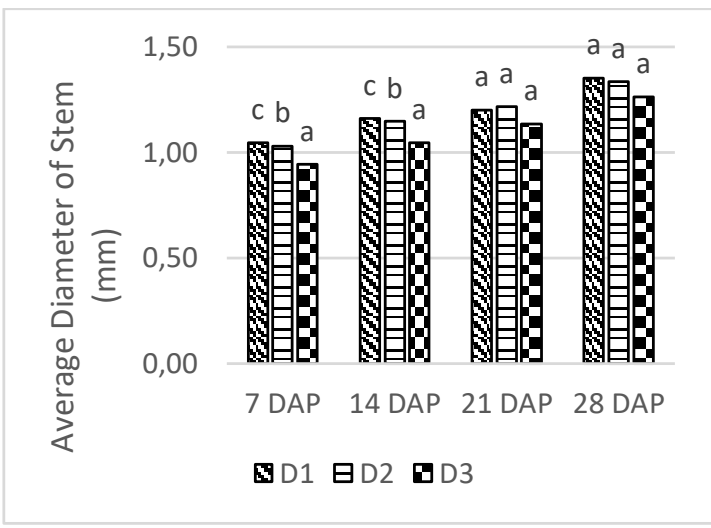

Figure 10. Average Diameter of Stem 7 28 DAP with Number of Section Treatment on Potato Buds.

Description :

- The mean value accompanied by the same letters between treatment combinations shows no significant difference according to the BNJ test level of $5 \%$.

In Figure 10 shows that the mean diameter of the treatment stem the number of sections differed very significantly at the age of 7 days, the mean value of D1 (number of segment 1) is higher than D2 (number of segment 2) and D3 (number of segment 3 ). Plant age of 14 days after planting showed significantly different, mean value of D1 (number of segment 1) was higher than D2 (number of segment 2 ) and D3 (number of segment 3). While at the age of 21 and 28 DAP is not significantly different.

Based on the results of the analysis of the mean variety when the roots appear, there is an interaction between the Radix Up treatment and the number of segments. The mean root time appeared faster in the Z1D3 treatment (Radix Up 1 and segment Number 3) with the time of root appearing 4.33 days (Figure 1). It is suspected that the two treatments collaborate with each other so that interactions occur between treatments that affect the emergence of roots. Based on the results of the research Fahmi et al. (2017), showed the percentage of rooted in dragon fruit plant cuttings on the stem with treatment giving NAA concentration, $100 \%$ rooted dragon fruit plant cuttings. Astutik research results (2007), chrysanthemum plantula roots grow fastest in the treatment of adding $0.1 \mathrm{mgl} /$ I NAA combined with BA $1 \mathrm{mgl} / \mathrm{I}$ which is 9.25 days and not significantly different from adding NAA $0.1 \mathrm{mg} / \mathrm{I}$ with kinetin 1 $\mathrm{mg} / \mathrm{I}$ which is 10.15 days.

Based on Figure 3, the average height of treatment plants did not have a significant effect on control (Rootone F). The control plant height variable (Rootone F) showed a higher average plant height compared to the treatment at the age of plants 7 to 28 DAP. Based on the results of the analysis of Radix Up treatment does not have a significant effect on plant height variables ranging from 7 DAP to 28 DAP. The treatment of the number of sections based on the results of the analysis of variance has a significant effect on plant height variables at 7 DAP and 28 DAP.

According to Campbell and Reece (2012), the main function of auxin is to stimulate cell elongation in young developing buds. Based on the research results of Usria et al. (2016), 25\% NAA ZPT administration showed higher increment which tended to be better. This is presumably because the low concentration of NAA can accelerate the formation of roots in cuttings and affect the absorption of water and nutrients as well as supporting the process of photosynthesis. The results of photosynthesis in the form of compounds that accelerate cell differentiation, thereby encouraging apical growth at the tips of plants that cause high growth.

Based on Figure 5 the mean number of leaves, the treatment was not significantly different from the control (Rootone F) at all plant ages. The variable 
number of leaves showed the average number of leaves more than the control at the age of plants 7,14 and 28 DAP, while at the age of 21 DAP showed more number of leaves at the control (Rootone $F)$. Based on the results of the analysis of the various Radix Up treatments did not have a significant effect on the variable number of leaves ranging from 7 DAP to 28 DAP (Figure 6). The treatment of the number of segments did not have a significant effect on the increase in the number of leaves ranging from 7 DAP to 28 DAP. (Figure 7).

Based on the research results of Ardaka et al. (2011), the number of leaflets that grew had a very significant effect $(P$ $<0.01$ ) on treated cuttings (atonic plant growth regulator with three sections) with leaf growth on days 100 and 130 days after planting an average of 2,53 strands and 2,90 strands. The number of leaflets is closely related to the number of cuttings that grow buds. Food reserves in the form of carbohydrates and nitrogen in cuttings can increase the number of leaves in plants. According to Suyadi and Maryana (2015), this is because cuttings with the number of segments 3 will make the number of leaves more, because more food reserves and buds more than one segment.

Based on Figure 8 the mean diameter of the stem, the treatment was not significantly different from the control (Rootone F) from the age of 7 DAP to 28 DAP. The variable diameter of the control rod (Rootone F) showed a higher average plant height compared to the treatment at the age of the plant 7 DAP after 28 DAP.
Based on the analysis of Radix Up treatment variety, it did not have a significant effect on stem diameter variables ranging from $7 \mathrm{DAP}$ to $28 \mathrm{DAP}$ (Figure 9). The treatment of the number of segments gives a real effect on the diameter of the stem at the age of 7 DAP and 28 DAP. According to Lakitan (2000), states that auxin stimulates elongation and enlargement of stems in several plant species.

\section{CONCLUSION}

Based on the research results, conclusions can be drawn, as follows:

1. There is a real interaction between the types of Radix Up and the number of segments in the observed variable when the root appears.

2. The treatment of giving Radix Up has no significant effect on observation variables of plant height, number of leaves and stem diameter.

3. The treatment of the number of segments significantly affected the plant height variable at the age of 7 DAP and 28 DAP, the diameter of the stem had a significant effect at 7 DAP and significantly affected at 14 DAP.

\section{REFFERENCES}

Ardaka, I M., I G. Tirta and D. P. Darma. 2011.

Effect of the number of segment and growth regulating substances on the growth of Pranajiwa cuttings (Euchresta horsfieldii (Lesch.) Benth.). Journal of Plantation Forest Research 82 Vol.8 No.2: $81-87$.

Astutik. 2007. Study of the Effect of Growth in the Development of Chrysanthemum Tissue Culture. Buana Science Vol 7 No 2: 113121.

Campbell, N. A and J. B. Reece. 2012. Biology. Penerbit : Benjamin Cummings. San Fransisco.

Fahmi, L. S., R. Sipayung, dan Meiriani. 2017. Effect of cuttings and 
provision of NAA ZPT on growth of Britton \& Rose's Red Dragon

Fruit Seedlings

(Hylocereus Costaricensis (Web) Britton \& Rose). Journal of Agroecotechnology Faculty of Agriculture USU. Vol.5. No.2 (38): 284- 297.

Lakitan, B. 2000. Physiological Growth and Development of Plants. Publisher of PT Raja Grafindo Persada, Jakarta.

Suyadi and Maryana. 2015. Successful Growth of Cured Seedlings in the Use of Various Amounts of Stem Cuttings and Time of Stabbing. Yogyakarta PGRI University. ISBN 978-602-73690-3-0

Ummah, K., and A. Purwito. 2009. Potato Cultivation (Solanum tuberosum, L.) with Special Aspects of Nurseries at Hikmah Farm, Pangalengan, Bandung, West Java. Paper presented at the confrence of the Department of Agronomy and Horticulture, Faculty of Agriculture IPB. Bogor.

Usrial, M., M. Mardhiansyah, dan T. Arlita. 2016. Response of Plant Growth Regulator (PGR) with Active Substances Naphthalene Acetic Acid (NAA) Against Growth of Stubble Cuttings from Stump Remaining Eucalyptus Pellita. Jom Faperta Vol.3 No.1 